\title{
On the geographic distribution and migration of I- and II-group eel larvae as studied during the 1979 Sargasso Sea Expedition
}

\author{
R. Kracht \\ Biologische Anstalt Helgoland (Zentrale); Notkestraße 31, \\ D-2000 Hamburg 52, Federal Republic of Germany
}

\begin{abstract}
During the 1979 Sargasso Sea Expedition, 423 larvae of Anguilla anguilla and 5 larvae of $A$. rostrata were caught on three Atlantic transects and two cruises in the Sargasso Sea. Results of the identification of the larvae by myomere counts, and limits of the occurrence of I- and II-group larvae are presented. Four standard fishing depths are compared. A range shallower than $25 \mathrm{~m}$ was found to be the optimal fishing depth by night for both larval length groups. The geographic distribution of length group I was observed in central and eastern North Atlantic. Available data indicate a migration of these larvae in a north easterly direction. Length measurements of the IIgroup larvae taken from catches on the European continental slope during the same expedition support this assumption.
\end{abstract}

\section{INTRODUCTION}

Since Schmidt (1925) published his classical study on the life history of the eel, the fate of the larval stages during their Atlantic phase and other problems have remained a matter of debate. Especially the long distance migration of the larvae has been discussed by many authors (Schmidt, 1924; Taning, 1938; Harden Jones, 1968; Vladykov \& March, 1975; Kleckner \& McCleave, 1980). This paper presents observations on the I- and IIgroup eel larvae caught during the 1979 Sargasso Sea Expedition. In addition, an attempt is made to investigate the occurrence of larvae in different fishing depths as well as their geographical distribution and migration.

\section{MATERIALS AND METHODS}

During the Sargasso Sea Expedition from February 12 to May 91979 with FRV "Anton Dohrn" (cruise No. 210/92) and RV "Friedrich Heincke" (cruise No. 160), plankton samples to be used especially for the capture of eel larvae were taken at the stations indicated in Figure 1. The eel larvae were caught by Isaac Kidds Midwater Trawls: one IKMT, $6 \mathrm{~m}^{2}$ opening and $0.5 \mathrm{~mm}$ meshsize, was towed by FRV "Anton Dohrn" for 45-70 min each haul in depths from 160-20 m (predominantly oblique hauls) at a towing speed of two knots; another IKMT, $2 \mathrm{~m}^{2}$ opening and $0.8 \mathrm{~mm}$ meshsize, was towed by RV "Friedrich Heincke" in standard fishing depths of 35, 50, 100 and $120 \mathrm{~m}$ wire (all horizontal hauls) for $60 \mathrm{~min}$ each haul at a towing speed of two knots. The 
leptocephali were preserved in $4 \%$ borax buffered formaldehyde - seawater solution and stored at room temperature $\left(18-20^{\circ} \mathrm{C}\right)$ in the dark. They were classified to genera using the identification key of Smith (1979); 423 larvae were identified as Anguilla anguilla (mean myomere number: $113.9 \pm 1.4), 5$ were $A$. rostrata.

\section{Vertical occurrence}

The vertical occurrence of 130 larvae was studied. These were caught from 20.00 to $00.00 \mathrm{~h}$ (local time) by 43 horizontal hauls at 4 standard fishing depths of 35, 50, 100 and $120 \mathrm{~m}$ wire. As the IKMT was not equipped with an opening closing device, only a rough idea of the optimal fishing depth can be presented. Samples with high numbers of larvae taken by this net are easily overestimated in studies dealing with vertical occurrence. So, from stations with several hauls at different depths, the relative number of larvae caught in these depths, related to the total catch at each of these stations, was used to estimate the catch per unit effort in each of the four standard fishing depths (Fig. 2).

\section{Horizontal distribution}

For the geographical distribution in length, the preserved larvae were measured on graph paper: total length with a class interval of $1 \mathrm{~mm}$ below. After 5-month preservation, there was an average shrinkage of $2.9 \%$. The two length groups were resolved by finding the mean length of the I-group by graphical method (Bhattacharya, 1967) and the standard deviation by the best fit of the I-group to the Gaussian distribution. All other lengths are II-group larvae (Fig. 3). The mean lengths of the larvae at 17 stations (Fig. 1, Table 1) are compared. Because of the low abundance of larvae some stations were pooled to stations groups; differences in mean lengths were tested by nonparametric tests (U test, $\mathrm{H}$ test), and for a length comparison of the II-group larvae, one station of another cruise ("Anton Dohrn" cruise December 1979) was included in station group B I. The abundance of larvae was plotted as number of larvae caught per hour towing in Figure 1.

\section{RESULTS AND DISCUSSION}

\section{Identification}

The myomere counts of 392 I- and II-group leptocephali of Anguilla anguilla averaged $113.9 \pm 1.4$ myomeres.

This is lower than the mean myomere number (114.68) of the 0-group larvae obtained from this expedition (Schoth, 1982) and also lower than the mean myomere number (114.73) found by Kleckner \& McCleave (1980). Differences in mean myomere counts are common and it should be kept in mind that those published for larvae of A. anguilla range from 115.58 (Jespersen, 1942) to 111.76 (Vladykov \& March, 1975). They attributed the extremely low counts to the counting technique, the different numbers of specimens, variation in size of specimens, and differences in collecting localities. The discussion concerning the "right" technique of counting is still going on. Boëtius (1980) succeeded in showing differences in the distribution of myomere counts of 


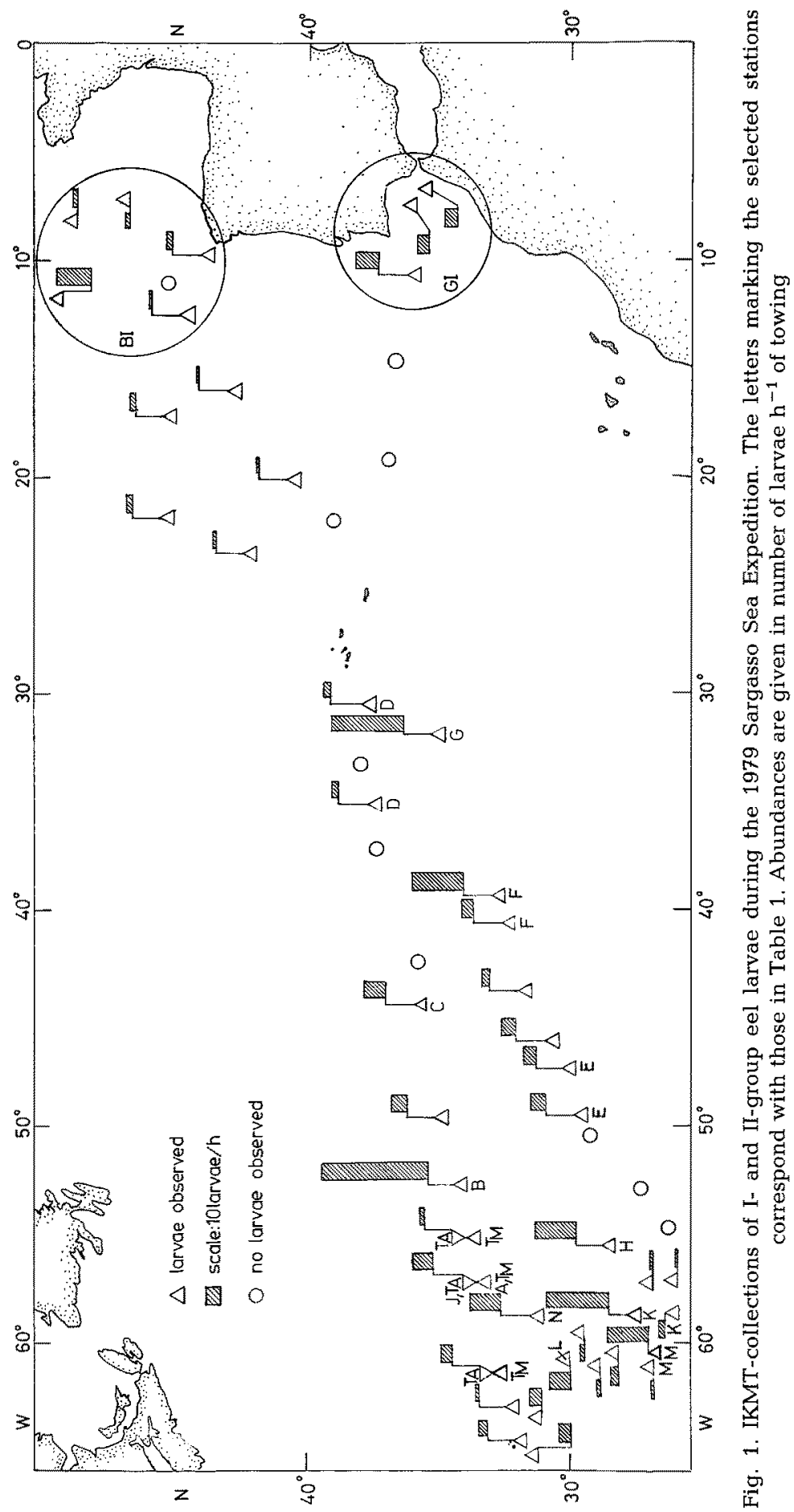




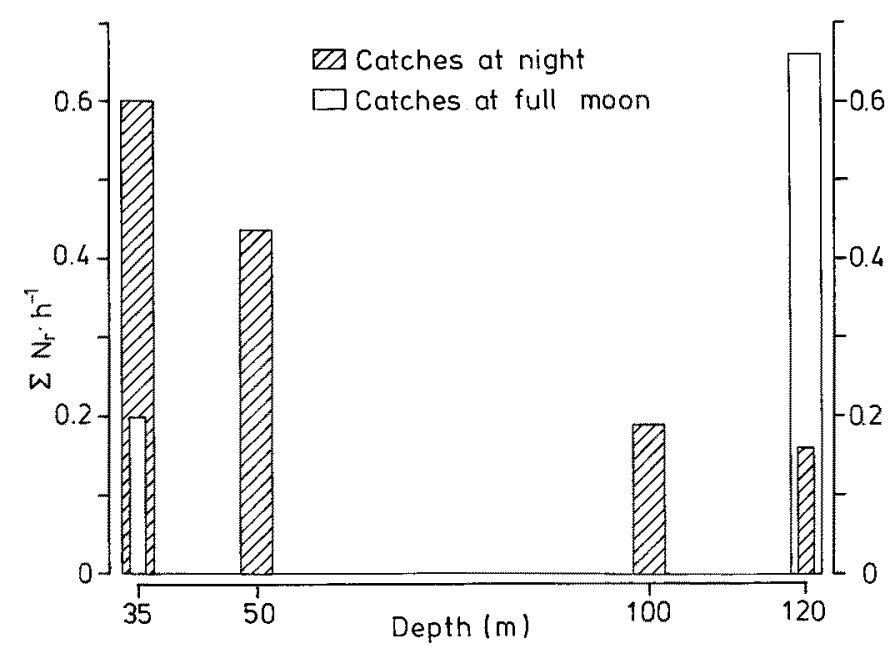

Fig. 2. Depth occurrence of the I- and II-group eel larvae from $20.00 \mathrm{~h}$ to 00.00 (local time). $\Sigma \mathrm{N}_{\mathrm{r}} \mathrm{h}^{-1}$ : Sum of relative numbers of larvae caught per hour towing. Relative numbers are related to the total catch at stations with several hauls in different fishing depths. Depths (m): length of the towing wire

ascending elvers in three European areas. It should be noted that most of the larvae, by far, of those counts mentioned here were caught west of $50^{\circ} \mathrm{W}$ (Fig. 1) (see also Kracht \& Tesch, 1981).

\section{Fishing depths}

The best of the 4 standard fishing depths is at $35 \mathrm{mw}$ (black bars in Fig. 2), but the optimal depth may be in even shallower waters. During the two and a half month cruise,

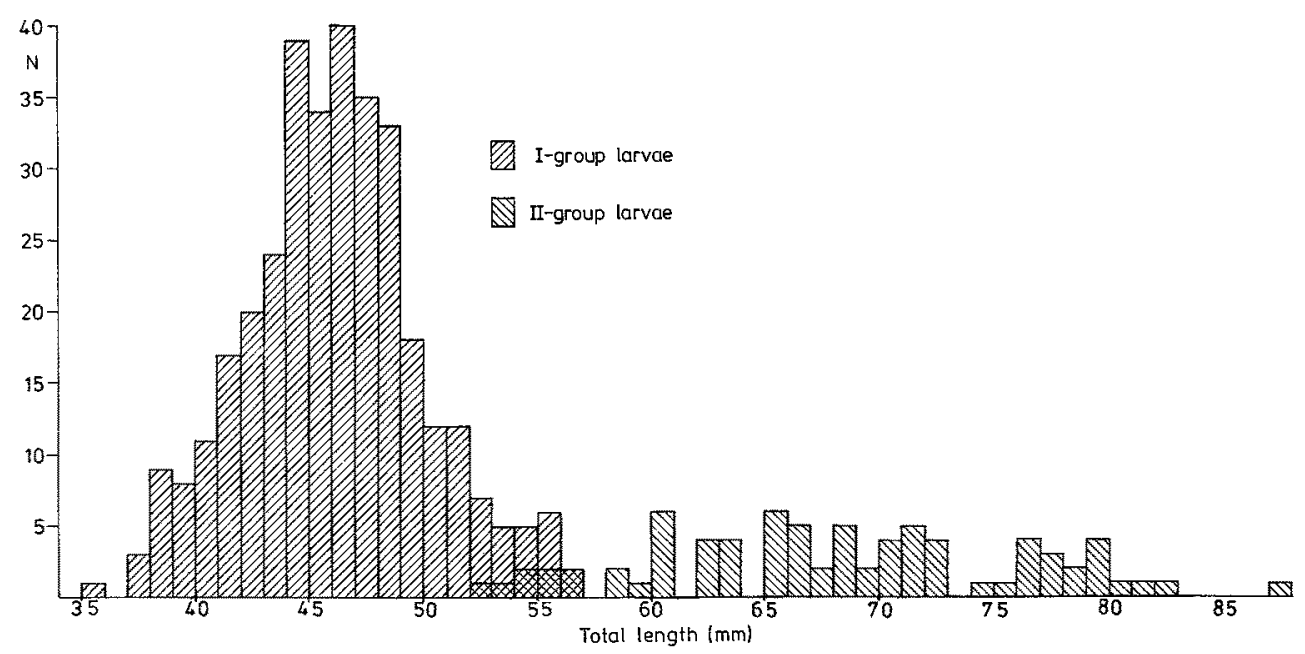

Fig. 3. Length-frequency distribution of the I- and II-group eel larvae from the 1979 Sargasso Sea Expedition. $\mathrm{N}=$ number of larvae. I-group larvae: $\overline{\mathrm{L}}=46.9 \pm 3.9 \mathrm{~mm} ; \mathrm{N}=340$; II-group larvae: $\overline{\mathrm{L}}=68.3 \pm 7.9 \mathrm{~mm} ; \mathrm{N}=75$; Best fit to the gaussian distribution (I-group): $\mathrm{H}_{\mathrm{O}}: \mathrm{P}\left(\chi^{2}>25.9\right)=0.1$ 
there were two periods of visible full moon. Depth preferences in these short periods were deeper (white bars, Fig. 2).

An optimal fishing depth at night of $35 \mathrm{mw}$ is in good agreement with results of Schmidt (1925), who found the larvae during darkness at a depth of $25 \mathrm{~m}$ to $50 \mathrm{~m}$ or "at times, at the surface itself". Depth preferences of II-group larvae found by Tesch (1980) at $65 \mathrm{~m}$ may be explained by another night fishing time from sunset to sunrise and by the comparatively larger number of metamorphosing specimens (Tesch, pers. comm.).

\section{Horizontal distribution}

On the northern Atlantic transect, the abundance of I-group larvae increases at first from west to east and then decreases $\left(T_{A}, T_{M}, B, C, D:\right.$ Fig. 1). On the southern transect (E, F, G: Fig. 1), there is a similar increase in abundance from west to east. Just as there is an overlap in length (Fig. 3), there is also an overlap in the geographical distribution of I- and II-group larvae. The easternmost catch of I-group larvae was at $31^{\circ} 30^{\prime} \mathrm{W}$, the westernmost catch of II-group larvae was at $53^{\circ} \mathrm{W}$.

Table 1. Mean length differences in time and place of the I- and II-group eel larvae from the 1979 Sargasso Sea Expedition. The letters of the stations correspond with those given in Fig. 1. $\overline{\mathrm{L}}=$ Mean length $(\mathrm{mm}), \mathrm{s} . \mathrm{d} .=$ standard deviation, $\mathrm{N}=$ number of larvae; mean length differences indicated by a trace are significant $(\mathrm{P}<0.01)$

\begin{tabular}{|c|c|c|c|}
\hline Station & Mean length difference (mm) & $\overline{\mathrm{L}} \pm$ s.d. & $\mathbf{N}$ \\
\hline $\begin{array}{l}\text { A } \\
B \\
C \\
D \\
E \\
F \\
G \\
H \\
I \\
K \\
\mathrm{~L} \\
M \\
N \\
T_{M} \\
T_{A} \\
\text { GI } \\
\text { BI }\end{array}$ & $\begin{array}{l}5.7 \\
2.6 \\
1.9 \\
5.8 \\
2.7\end{array}$ & $\begin{array}{l}45.7 \pm 2.6_{i} \\
46.4 \pm 2.2 ; \\
46.8 \pm 5.2 ; \\
52.5 \pm 4.5 ; \\
48.1 \pm 3.2 ; \\
46.9 \pm 3.9 ; \\
53.8 \pm 3.5 ; \\
45.7 \pm 2.9 ; \\
48.3 \pm 2.4 ; \\
41.2 \pm 1.7_{i} ; \\
43.1 \pm 1.7_{i} ; \\
39.1 \pm 1.5_{i} ; \\
44.9 \pm 2.0_{i} \\
45.5 \pm 2.5_{i} \\
48.2 \pm 2.2 ; \\
70.0 \pm 5.6_{i} ; \\
75.8 \pm 5.7_{i}\end{array}$ & $\begin{array}{l}25 \\
71 \\
16 \\
11 \\
12 \\
22 \\
29 \\
14 \\
21 \\
16 \\
17 \\
15 \\
11 \\
37 \\
26 \\
43 \\
26\end{array}$ \\
\hline
\end{tabular}

Larvae caught at the same geographical position after an interval of one month show a difference in mean length of $2.7 \mathrm{~mm}$ (see Stations $\mathrm{T}_{\mathrm{M}}, \mathrm{T}_{\mathrm{A}}$ in Fig. 1 and Table 1). Because of this length difference in time, only those I-group stations with time differences smaller than 6 days compared to gain a comparison of mean length in place (Table 1). The mean 
length of the I-group larvae increases from south to north and, excluding station-group $F$, in a west-east direction. From south to north there is an average length increase of 1.1 $\mathrm{mm} / 100$ nautical miles (station groups $\mathrm{HI}, \mathrm{KL}, \mathrm{MN}$ ). On the west-east transects the mean length increase is $0.6 \mathrm{~mm} / 100 \mathrm{~nm}$ (stations $A B C D, E F G$ ). A comparison of mean lengths of the station groups near the European continental slope (GI, BI, see Table 1 and Fig. 1) show that the II-group larvae near Gibraltar (GI) are significantly smaller $(5.7 \mathrm{~mm})$ than those caught in the Bay of Biscay (BI).

The occurrence, in the Bay of Biscay, of longer II-group larvae than those caught near Gibraltar does not confirm Schmidt's (1909) assumption that larvae from northern areas are smaller than those from southern areas. But in earlier larvae collections a length difference similar to that in the catches of 1979 can be found: the length of larvae caught by RV "Thor" in February 1922 near Gibraltar was reported to be $66-67 \mathrm{~mm}$ (Schmidt, 1925); larvae found by Tesch (1980) in the Bay of Biscay were about $70 \mathrm{~mm}$ in mean length. A similar increase in length of the I-group larvae from south to north and from west to east indicates a migration in a north-easterly direction. This confirms the results of Schmidt (1924). It is not in agreement with the hypothetical drift charts of Harden Jones (1968) and the assumption of the distribution of the I-group larvae of A. anguilla by the Gulf Stream. The geographic distribution in length of the II-group larvae near the European continental slope does not correspond either with a transport of the larvae by the North Atlantic current via the Portugal Current to Gibraltar. Other transport mechanisms or active movement to the northeast would correspond better with the geographical length distribution of the I- and Il-group larvae of $A$. anguilla and should be taken into consideration.

Acknowledgements. Many thanks to Dr. F,-W. Tesch for the chance to participate on the cruise, Captain H. Falke and his crew for nautical management, M. Schoth for myomere counting and length measurements of many larvae, J. Marschall, C. Ramm, and E. Schneider for drawing the figures, Dr. H. Rosenthal for his critical reading of the original manuscript, Mrs. C. Berger for her help in the translation of the text, and Mrs. C. Schuster for typing the mamuscript.

\section{LITERATURE CITED}

Bhattacharya, C. G., 1967. A simple method of resolution of distribution into Gaussian components. - Biometrícs 23, 115-135.

Boëtius, J., 1980. Atlantic Anguilla. A presentation of old and new data of total numbers of vertebrae with special reference to the occurence of Anguilla rostrata in Europe. - Dana 1, 93-112.

Harden Jones, F, R., 1968. Fish migration. Arnold, London, 325 pp.

Jespersen, P., 1942. Indo-Pacific leptocephalids of the genus Anguilla. Systematic and biological studies. - Dana Rep. 22, 1-128.

Kleckner, R. \& McCleave, J. D., 1980. Spatial and temporal distribution of Anguilla rostrata and Anguilla anguilla leptocephali found in North-American ichthyoplankton collections. - C. M./ ICES M21.

Kracht, R. \& Tesch, F.-W., 1981. Progress report on the eel expedition of R. V. "Anton Dohrn" and R. V. "Friedrich Heincke" to the Sargasso Sea 1979. - Environ. Biol. Fish. 6, 371-375.

Schmidt, J., 1909. Remarks on the metamorphosis and distribution of the larvae of the eel (Anguilla vulgaris, Turt.). - Meddr Kommn Havunders. (Fisk.) 3, 1-17.

Schmidt, J., 1924. The transatlantic migration of the eel larvae. - Nature, Lond. 113, 12.

Schmidt, J., 1925. The breeding places of the eel.-Rep.Smithson. Instn 1924, 279-316.

Schoth, M., 1982. Taxonomic studies on the 0-group eel larvae (Anguilla sp.) caught in the Sargasso Sea in 1979. - Helgoländer Meeresunters. 35, 279-287. 
Smith, D. G., 1979. Guide to the leptocephali (Elopiformes, Anguilliformes, and Notacanthiformes). - NOAA tech. Rep. NMFS Circ. 424, 1-39.

Tåning, A. V., 1938. Deep-sea fishes of the Bermuda Oceanographic Expeditions. Family Anguillidae. - Zoologica, N. Y. 23, 313-318.

Tesch, F.-W., 1980. Occurence of eel Anguilla anguilla larvae west of the European continental shelf, 1971-1977. - Environ. Biol. Fish. 5, 185-190.

Vladykov, V. \& March, H., 1975. Distribution of leptocephali of the two species of Anguilla in the western North Atlantic, based on collections made between 1933 and 1968. - Syllogeus 6, 1-38. 